\title{
River flows and water wars: emerging science for environmental decision making
}

\author{
N LeRoy Poff ${ }^{1}$ J David Allan ${ }^{2}$, Margaret A Palmer ${ }^{3}$, David D Hart ${ }^{4}$, Brian D Richter ${ }^{5}$, Angela H Arthington ${ }^{6}$, \\ Kevin H Rogers ${ }^{7}$, Judy L Meyer ${ }^{8}$, and Jack A Stanford ${ }^{9}$
}

Real and apparent conflicts between ecosystem and human needs for fresh water are contributing to the emergence of an alternative model for conducting river science around the world. The core of this new paradigm emphasizes the need to forge new partnerships between scientists and other stakeholders where shared ecological goals and river visions are developed, and the need for new experimental approaches to advance scientific understanding at the scales relevant to whole-river management. We identify four key elements required to make this model succeed: existing and planned water projects represent opportunities to conduct ecosystem-scale experiments through controlled river flow manipulations; more cooperative interactions among scientists, managers, and other stakeholders are critical; experimental results must be synthesized across studies to allow broader generalization; and new, innovative funding partnerships are needed to engage scientists and to broadly involve the government, the private sector, and NGOs.

Front Ecol Environ 2003; 1(6): 298-306

$\mathrm{C}$ onflicts based on the perceived needs of ecosystems versus humans for fresh water are increasingly seen in the news. In the US, a fiery debate has erupted in the Klamath basin of Oregon and California, where farmers have protested the loss of irrigation water to protect endangered fish, and where over 30000 chinook salmon and other fish recently died, perhaps due to insufficient water quantity and/or quality (Levy 2003; Figure 1). The states of Georgia, Alabama, and Florida have been

\section{In a nutshell:}

- The ecological sustainability of river ecosystems is threatened by the extensive hydrologic alterations carried out by humans

- Despite the strong conceptual basis for sustainable river management, scientists are challenged to define ecosystem needs clearly enough to guide policy formulation and management actions that balance competing demands and goals

- An alternative model of collaboration between scientists, managers, and other stakeholders to perform large-scale river experiments is emerging around the world

- Innovative funding partnerships between government agencies, not-for-profit foundations, and the private sector are required to advance the scientific basis of water management

${ }^{1}$ Dept of Biology, Colorado State Univ, Fort Collins, CO 80523 (poff@lamar.colostate.edu); ${ }^{2}$ School of Natural Resources and Environment, Univ of Michigan, Ann Arbor, MI 48109; ${ }^{3}$ Dept of Entomology, Univ of Maryland, College Park, MD 20742; ${ }^{4}$ Patrick Center for Environmental Research, Academy of Natural Sciences, Philadelphia, PA 19103; ${ }^{5}$ The Nature Conservancy, Charlottesville, VA 22901; ${ }^{6}$ Cooperative Research Centre for Freshwater Ecology, Griffith Univ, Nathan, QLD 4111, Australia; ${ }^{7}$ Centre for Water in the Environment, Univ of the Witwatersrand, Johannesburg, South Africa; ${ }^{8}$ Inst of Ecology, Univ of Georgia, Athens, GA 30602; ${ }^{9}$ Flathead Lake Biological Station, Univ of Montana, Polson, MT 59860 engaged for over a decade in contentious negotiations over water allocation in the Apalachicola-Chattahoochee-Flint River basin, with demands coming from the growth of metropolitan Atlanta, agricultural irrigation, and the Apalachicola Bay oyster fishery (Richter et al. 2003b).

In New Zealand, a debate rages over how to allocate enough water to maintain the ecological needs of the Rangitata River while addressing the water demands of the dairy industry (Robson 2002). Similar conflicts between water requirements for irrigation and environment along the Lower Balonne River system in Australia have prompted an independent review of the science underlying river condition assessments and environmental flow recommendations (Cullen et al. 2003). As human population growth and climate change impose new constraints on the spatial and temporal distribution of water (Postel et al. 1996; Vörösmarty et al. 2000), we may expect more such water conflicts, and even environmental water "wars", such as in the Klamath basin. Increased human demand will compete with the real needs of freshwater ecosystems (Baron et al. 2002; Poff et al. 2002; Arthington and Pusey in press).

The challenge now facing river scientists is to define ecosystem needs clearly enough to guide policy formulation and management actions that strive to balance competing demands and visions. Is the current science up to this challenge? Recent events in the Klamath basin suggest a number of problems. An interim National Research Council (NRC) report evaluating the science underlying the federal management of water to protect endangered fishes in the Klamath highlighted the uncertainty of available science to support decision making (NRC 2002c). The Klamath conflict, and many others around the world, 
provide dramatic evidence that improvements are needed in the science, the decision-making process, or probably both.

Society is clearly willing to invest in flow management for ecological restoration. For example, the Northwest Power Planning Council and Bonneville Power Administration have spent several billion dollars over the past decade on salmon restoration in the Columbia River system, with considerable emphasis on flow and habitat restoration (ISG 2000). The Tennessee Valley Authority has spent more than $\$ 44$ million modifying dam operations to increase flows and improve water quality (Bednarek 2002; Figure 2). The 7-day experimental flood of the Grand Canyon in 1996

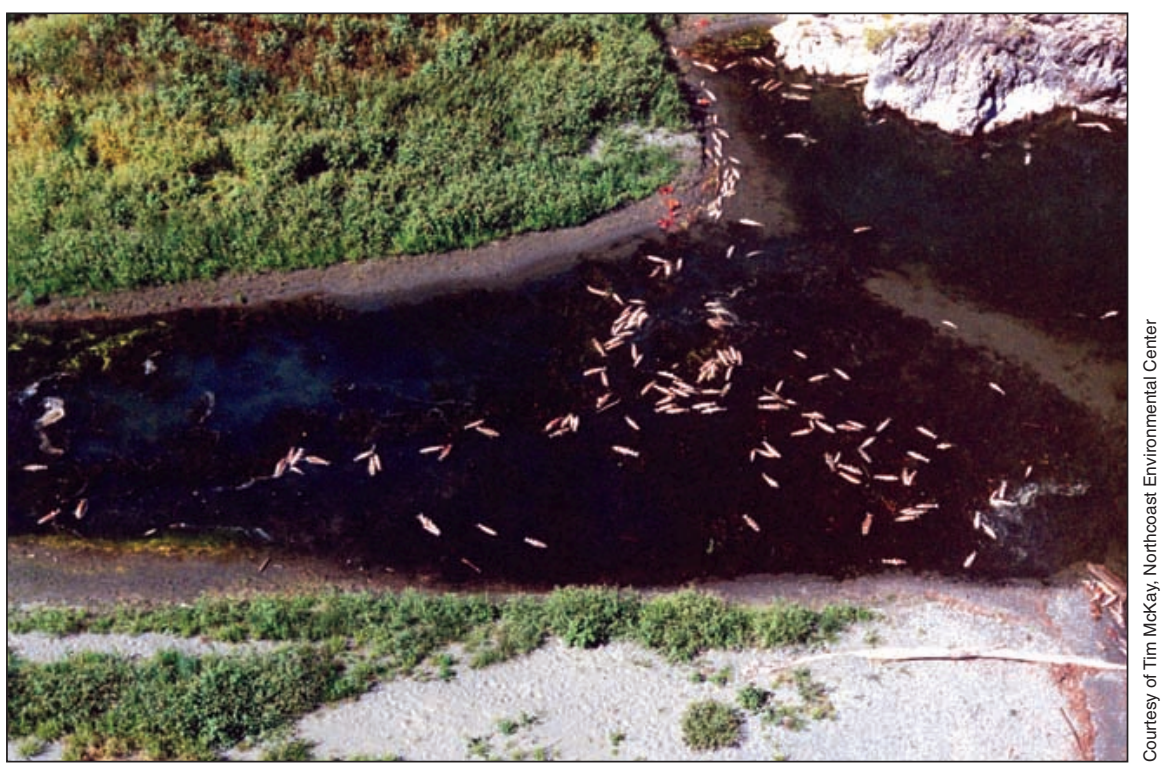

Figure 1. Dead salmon in the Klamath River, September 2002. cost \$2.5 million in lost hydropower revenue (Patten and Stevens 2001). Australia's plans to provide an environmental flow equal to $28 \%$ of the mean annual flow for the Snowy River, to restore ecosystem integrity and recreational opportunities, will cost at least US\$216 million (Pigram 2000).

Already, scientists in North America, South Africa, Australia, New Zealand, and Europe are actively advising the public and river managers on the necessary quantity and timing of river flow needed to maintain desired ecological characteristics. Such advice is being provided in diverse political contexts, ranging from the cooperative to the controversial. In the US, scientists have helped guide efforts to recover endangered species in rivers like the Klamath, the Colorado, and the Missouri (NRC 2002b), to restore degraded flagship ecosystems such as the Florida Everglades (Holling et al. 1994), and to define the flows needed to protect ecological integrity on federally-owned lands (NPS 1996). In addition, scientists are now being asked to project the ecological responses to dam removal in the US (Hart et al. 2002), or in Australia's MurrayDarling River Basin, to advise on how to "press dams into environmental service", to provide so-called "environmental flows" (D Blackmore, pers comm). However, the calculus of environmental, economic, and social costs and benefits in many of these restoration efforts is complex, and scientific uncertainty further complicates matters (Pigram 2000; Bunn and Arthington 2002; Stanley and Doyle 2003).

Although society is often willing to invest in the restoration and protection of rivers, there are also high expectations for measurable ecological returns. Over the past decade, scientists have developed a solid conceptual understanding of the importance of natural flows for river ecosystems (Naiman et al. 1995; Poff et al. 1997; Puckridge et al. 1998), and this can provide a strong foundation for large-scale water manipulations and environmental flow restoration strategies (Stanford et al. 1996; Arthington
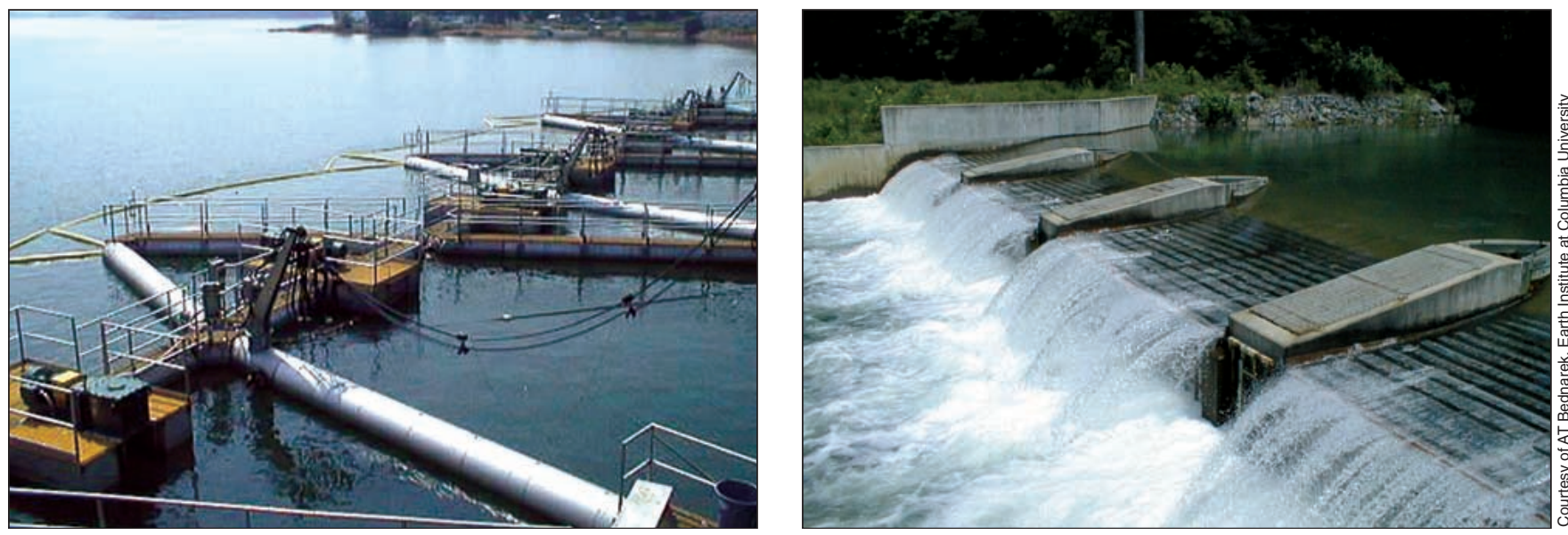

Figure 2. Improvements in Tennessee Valley Authority dam operations include (left) surface water pumps in the Douglas Reservoir (French Broad River, NC), designed to push oxygenated water from the surface to deepwater turbines, and (right) infuser weirs downstream of Chatuge Dam (Hiawassee River, NC), designed to provide both minimum flow and dissolved oxygen. 


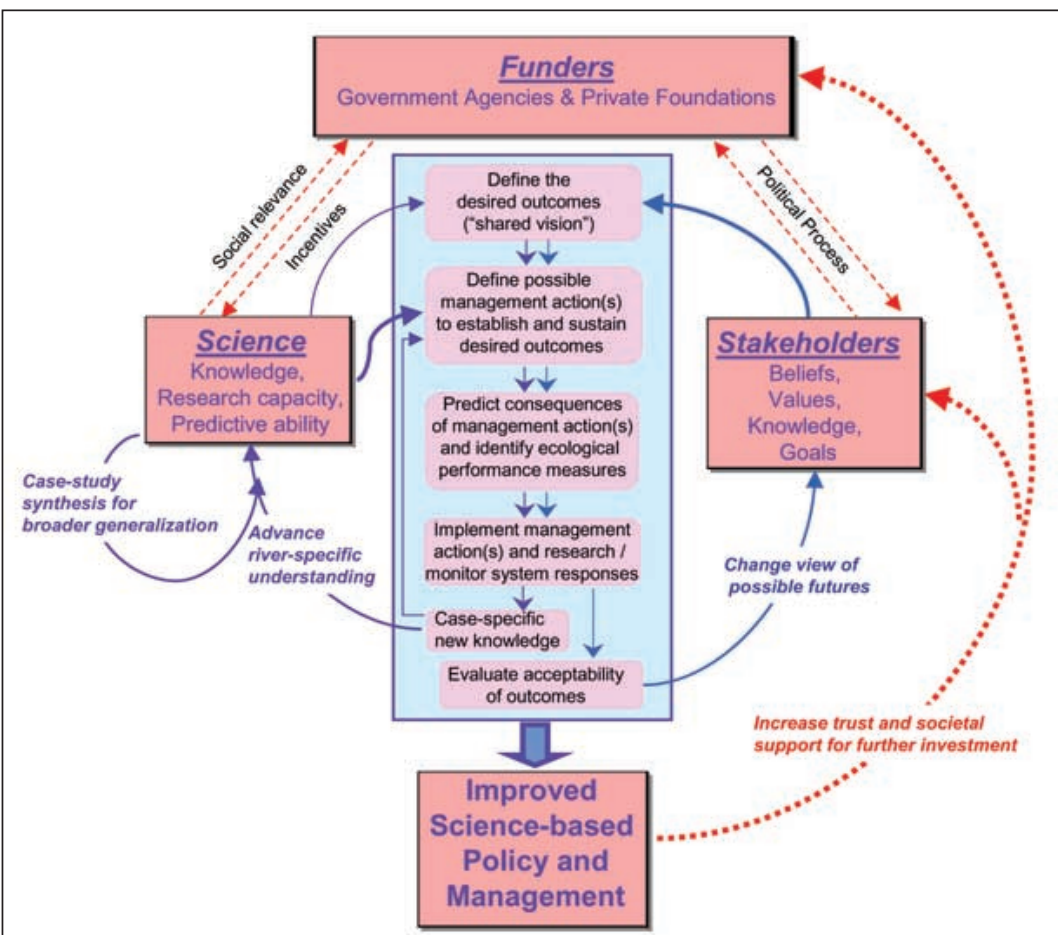

Figure 3. Conceptual flow diagram illustrating interactions and feedback loops between science, stakeholders, and funders in the pursuit of improved sciencebased policy and management of river ecosystems. This is accomplished by using existing water management structures as opportunities to conduct large-scale learning experiments.

and Pusey in press). Indeed, the "Natural Flows Paradigm" (Poff et al. 1997) is already becoming the blueprint for river corridor restoration and flow management in several countries, particularly Australia and South Africa. However, water managers and other stakeholders are now demanding more than just a strong conceptual understanding to guide the management of individual rivers such as the Klamath. They are asking, how much flow restoration is necessary to ensure ecological sustainability? How natural do flow quantity, seasonal timing, and water quality need to be to achieve the desired ecological outcomes?

New approaches to research, management, and policy development are needed to answer these critical questions. Elements of such approaches are emerging from various countries, with considerable progress being reported at international conferences in the US (Managing River Flows for Biodiversity, Fort Collins, Colorado, July 2001), South Africa (Environmental Flows for River Systems, Cape Town, March 2002), Cambodia (Second Large Rivers Symposium - LARS 2, Phnom Penh, February 2003), and Australia (The Nature, Causes, and Consequences of Variability in Large Rivers, Albury NSW, July 2003). Our growing understanding of two major shortcomings of past scientific investigations has stimulated innovations in the practice of river science. First, conventional research methods (eg small-scale experimentation and large-scale comparative studies) are often insufficient for gaining adequate ecological understanding to support effective decisions for river-specific restoration and management. Second, to achieve desirable ecological outcomes, scientists must also see themselves as partners at the table with resource managers and other stakeholders in a collaborative process, so that scientific understanding, management strategies, and societal goals are effectively integrated.

\section{Strengthening roles}

Based on the growing recognition that more effective approaches are needed, we propose four steps to strengthen the roles of science and society in managing rivers (and other fresh waters) to meet human and ecosystem needs. The conceptual framework linking these four steps is presented in Figure 3.

\section{Step 1: Implement more large-scale river experiments on existing and planned water management projects}

We have achieved major theoretical advances in our understanding of how streams and rivers function. Nevertheless, fundamental problems of uncertain knowledge and limited predictive capability continue to beset the science underlying river ecosystem management. This uncertainty arises both from irreducible ecosystem complexity, and from the limited transferability of general ecological understanding to site-specific situations. A learning-bydoing approach therefore becomes a prerequisite for the effective management of complex river ecosystems (Rogers in press). Because extrapolating results from traditional small-scale experiments to the much larger scales relevant to river management requires untested assumptions of transferability in scaling up (Walters and Korman 1999), well-designed, large-scale experiments and monitoring arguably offer the best approach to learning in the long run (Walters 1997). This, of course, is the core principle of adaptive management. Even so, a major limitation in advancing scientific knowledge to guide ecological flow management is the lack of opportunities to conduct large-scale experiments, where whole-system responses can be evaluated at scales that match management actions (Kingsford 2000; Bunn and Arthington 2002). Currently, far too many opportunities are being missed to learn from river flow manipulations at these larger scales.

We argue that water development and river restoration projects should be routinely established as scientifically credible, ecosystem-scale experiments, where water management activities represent treatments to test specific 
ecological hypotheses. The results of such experiments will greatly advance our scientific capacity for ecological prediction, and promote more efficient and ecologically sustainable water management. For example, extensive monitoring in conjunction with the planned 1996 Grand Canyon flood evaluated specific hypotheses and produced new understanding about sediment availability and habitat forming processes, information that is now being used to guide future flow manipulations (Rubin et al. 2002). A 5-year research program on the Green River below Utah's Flaming Gorge Dam included experimental flow releases to better establish the specific requirements of endangered fish species, leading to a set of flow and temperature recommendations to guide management of this large river (Muth et al. 2000).

Many river basins have multiple impoundments or other types of water developments that cumulatively alter flow regimes (Pringle 2001). We should therefore also seek opportunities to conduct experimentation at the scale of entire river basins, taking into account spatially distributed water control structures (Figure 4). For example, by coordinating critical components of the natural flow regime (such as high flow pulses at specific times) across multiple water control structures, we could assess ecological benefits relative to existing conditions in a powerful, integrated manner across many ecological scales. Current efforts in the Yakima River in Washington State (Stanford et al. 2002) provide an encouraging example, as do some governmental programs aimed at coordinating restoration activities for large river basins. For example, in Australia's Murray-Darling River Basin, a federal initiative has established a community-government partnership "to promote and coordinate effective planning and management for the equitable, efficient, and sustainable use of the water, land, and other environmental resources", using adaptive management (MDBI 2003). The California Bay-Delta Program represents a similar initiative in the US (CALFED 2001).

Experiments are powerful agents for learning, but even the best designed experiment cannot resolve all the scientific uncertainty associated with an ecosystem's response to human manipulations. Indeed, scientists have recently criticized ecosystem management for its overemphasis on experimentation (Holling and Allen 2002). Furthermore, the use of the word "experiment" may raise concerns among managers and stakeholders who are uncomfortable implementing actions with uncertain outcomes. Neutral language, such as "researching ecosystem response to a change in driving variables", may more effectively moti- vate them. Clearly, other valid modes of scientific inference, such as comparative and correlative studies (Pickett et al. 1994), represent essential elements in advancing river science (see Step 3 below). Nonetheless, experiments provide learning at the appropriate scale with the potential to discriminate between competing hypotheses (Holling and Allen 2002) and must therefore be pursued if we are serious about fine-tuning river management for ecological sustainability. Dismissing large-scale experiments as too socially intrusive or "risky" represents a misunderstanding of science's role in sustainable management.

A medical analogy illustrates this important point. Adopting experiments as a mode of learning is analogous to the widely accepted practice of using clinical trials with human subjects (also complex systems) in the hope of improving medical therapies. Experiments in resource management should not reflect the engineering model of a quick fix to the problem, but rather the medical model of engaging the problem in all its complexity, with the intention of achieving more efficient pathways towards sustainability (M Healey, pers comm).

\section{Step 2: Engage the problem through a collaborative process involving scientists, managers, and other stakeholders}

Clearly, an effective study design is essential to maximize the lessons learned from large-scale ecosystem manipula- 
tions. This can only occur if two conditions are met, both of which represent challenges to the prevailing culture of science. The first bears on how scientists interact with each other in advancing scientific understanding. The second relates to how scientists interact with other stakeholders, managers, and regulators in any ecologically and socially complex management experiment.

First, river science obviously comprises multiple disciplines, so interdisciplinary scientific teams must be involved from the outset (NRC 2002a). Exclusion of key disciplines or post facto integration of teams is inefficient at best and doomed to failure at worst (Benda et al. 2002). Not only must biologists of various subdisciplines interact with physical scientists such as hydrologists and geomorphologists, but social science knowledge about human values, perceptions, behaviors, and institutional culture also need to be integrated into the science that guides river management (Naiman et al. 2002; Nilsson et al. in press). With such integration, science can better inform the decision-making process, despite the complexity of coupled human-natural systems. Interdisciplinary teams can construct various options, so that the uncertain outcomes of proposed actions can be weighed against a wide range of possible outcomes and alternative actions (Carpenter 2002; King et al. in press). Scientific uncertainty is thus positively transformed into information that can promote hypothesis generation, experimentation, and improved decision making (Bradshaw and Borchers 2000).

Second, there is growing recognition that the role of the scientist as a disinterested expert fails when confronting complex (or "wicked") problems typical of managing ecosystems for both ecological sustainability and societal needs (Ludwig 2001; Rogers in press). Attempts by scientists to avoid ecological complexity by focusing on relatively simple questions with narrow technical solutions (such as minimum environmental flow needs for individual, well-studied species) run the risk of undermining societal confidence in science's ability to contribute insightfully to solving difficult environmental problems. Indeed, science alone cannot "solve" environmental problems, because there are a multitude of legitimate perspectives and desired outcomes that defy objective, technical resolution (Allen et al. 2001; Ludwig 2001). We emphasize, however, that scientists need not sacrifice the validity of their advisory and decision-making roles, but to be effective they must be willing to work with other stakeholders towards common goals in a more democratic process (Ludwig 2001; Rogers in press).

Indeed, this interaction with other stakeholders is essential because ecological systems are inextricably coupled with social systems (Folke et al. 2002; Pfirman and AC-ERE 2003). This coupling provides a context not only for how scientists design experiments and test models, but also for exploring what is desired and what is achievable in a given ecological, social, and political context (Folke et al. 2002). Flow management for rivers in Kruger National Park, South Africa, offers an excellent example of how science and stakeholder values have been integrated in setting ecological goals. River scientists facilitated discussions among a range of water users outside the park to develop a consensus vision for the ecological health of the park's river ecosystems. Qualitative stakeholder objectives were translated into quantitative management targets (Rogers and Bestbier 1997) that now guide water allocation in the river basins. In the US, flow releases in the Colorado River have also involved early engagement of science in an experimental mode, with extensive participation of stakeholders, including federal and state agencies, energy production organizations, Native American tribes, and recreational and environmental organizations (GCMRC 2003). As another example, university scientists, Nature Conservancy staff, and the US Army Corps of Engineers are currently compiling and assessing biophysical information on the Savannah River in South Carolina and Georgia, to develop flow prescriptions for long-range water allocation planning that the Corps facilitates (Richter et al. 2003b).

One of the grand challenges to effectively creating collaborative partnerships lies in the organizational mindset and culture of the collaborating partners. Panel 1 contrasts the leadership style, organization structure, and culture of conventional (traditional) versus adaptive approaches to problem definition, goal setting, and decision making. For scientists, participation in this adaptive management framework requires a willingness to acknowledge uncertainty and draw more qualitatively on the latest scientific knowledge, and even to give a best guess as to how to proceed (Rogers in press). Involvement in such processes can be very time consuming and may draw researchers into situations where stakeholder conflict can arise. Professional incentives and safeguards are therefore needed, to ensure that capable researchers actively participate. It is important that peers and colleagues respect and acknowledge researchers, as a professional incentive, although this is often not the case. At a more interpersonal level, if managers and other collaborating stakeholders express a willingness to participate in a more equitable and cooperative process of problem definition, goal setting, and decision making, then scientists will be more encouraged to commit to active involvement.

\section{Step 3: Integrate case-specific contextual knowledge into broader scientific understanding}

Well-designed experiments, like those occurring in the Grand Canyon, represent case studies that provide raw material for new generalizations about river management and restoration. A major challenge in the synthesis of such case studies lies in accounting for the local human-natural contexts of individual cases that may be difficult to translate into broader generalization. Some variation in outcomes of management experiments is to be expected; our knowledge base must therefore be 


\section{Panel 1. Changing the organizational mindset for catchment management}

Solutions to environmental problems require not only the best efforts of scientists, but collaborative problem definition, goal setting, and decision making. An active partnership of scientists, managers, and society (ie all stakeholders) is necessary because problems such as water conflicts are multidimensional and multidisciplinary. This table outlines critical changes that are needed. Adapted from Rogers, Roux, and Biggs' (2000) discussion of lessons from bureaucracies, business, and resource management.

\begin{tabular}{|c|c|c|}
\hline & Conventional bureaucracies & Adaptive organizations \\
\hline Leadership style & $\begin{array}{l}\text { Primarily command-and-control } \\
\text { Transactional/paper shuffling } \\
\text { Generative (designer, teacher, steward) }\end{array}$ & Primarily to coordinate and facilitate \\
\hline Structure & $\begin{array}{l}\text { Functional hierarchies } \\
\text { Vertical communication } \\
\text { Work for one boss }\end{array}$ & $\begin{array}{l}\text { Dynamic teams with blurred boundaries } \\
\text { Horizontal dialogue } \\
\text { Work with colleagues across boundaries }\end{array}$ \\
\hline Culture & $\begin{array}{l}\text { Thinking at the top, doing at the bottom } \\
\text { Collect data and manage information } \\
\text { Follow rules and regulations } \\
\text { Internal competition } \\
\text { This-is-our-product/empire syndrome } \\
\text { Observe and criticize mistakes } \\
\text { Rather make no decision than a wrong one } \\
\text { View uncertainty, complexity and change as } \\
\text { threats }\end{array}$ & $\begin{array}{l}\text { Develop common purpose through collaborative goal setting } \\
\text { Generate, codify, and transfer knowledge } \\
\text { Driven by vision and values } \\
\text { Integrated operations across stakeholder-service provider } \\
\text { boundaries } \\
\text { Enthusiastic sharing of knowledge (trust and openness) } \\
\text { Learn and adapt through hypothesis testing and critical reflection } \\
\text { Recognize when new knowledge allows you to make the next } \\
\text { better decision } \\
\text { Treat uncertainty, complexity, and change as opportunities } \\
\text { for learning and improvement }\end{array}$ \\
\hline
\end{tabular}

informed by many more case studies across diverse settings. Individual river experiments need to be integrated into a broader, comparative framework that sustains an adaptive cycle of general understanding, which in turn supports hypothesis testing that feeds back into generalization (Holling and Allen 2002; Figure 3).

Unfortunately, many current opportunities are already being lost. For example, to date only a handful of the more than 500 dam removals in the US have been initiated to achieve specified ecological goals. Moreover, few of these removals have been accompanied by scientific studies (Hart et al. 2002; Figure 5). Even had this more often been the case, the difficult task of broader synthesis would still be required. Typically, this synthetic step is not taken, even where opportunities present themselves. In the Missouri River Basin, for example, the NRC reports that thousands of small-scale studies exist, but they have not been integrated to address complex ecosystem management issues, making decisions more difficult and contentious (NRC 2002b). The challenge of integration is not trivial, but new techniques hold promise for integrating disconnected case studies to guide ecosystem management. For example, fuzzy cognitive mapping (Hobbs et al. 2002) can be used to distill expert scientific judgments about ecosystem components and interactions to identify effective management strategies that account for stakeholder concerns. Bayesian networks, which express complex system behavior probabilistically, also facilitate predictive modeling based on knowledge and judgment. They thereby enhance basic understanding without requiring prohibitive amounts of detail (Reckhow 1999).

\section{Step 4: Forge new and innovative funding partnerships}

Lack of funding for the scientific process described here is one major reason for the paucity of effective case studies. Such research may seem too mission-oriented for agencies like the US National Science Foundation, whereas many agencies that fund large-scale river management (eg US Corps of Engineers, Bureau of Reclamation) do not have a mandate to conduct research that assesses ecological outcomes. We need innovative funding mechanisms to enable the science required to successfully guide and evaluate river management decisions with ecological and societal consequences. While there has been some recent increase in funding for investigations of the complex interactions between human and natural systems (Pfirman and ACERE 2003), there are still far too few opportunities to focus research on real-world conservation and management actions, and thus to simultaneously expand our understanding and improve the basis for decision making (NRC 2002a; Arthington and Pusey in press).

River science offers an excellent arena for creating unconventional funding partnerships, because society will continue to invest immense sums of money to operate the water infrastructure. We believe that this societal investment should be extended to facilitate large-scale learning 
opportunities, where relatively small investments by traditional science funding agencies, such as the National Science Foundation and the US Environmental Protection Agency, can promote more active research involvement and thus leverage important scientific gains of broad social benefit.

Given the demonstrated desire of many societies to promote environmental quality (Shabecoff 2000), democratic governments can play a catalytic role in supporting research to focus on and learn from large-scale river restoration projects. Governments own and operate thousands of dams and countless other water control structures around the world. They should act now to address many of the ecological problems these facilities have caused (WCD 2000), particularly given the evidence that substantial ecological benefits can be realized with minimal or no economic sacrifice by existing water users (for example, see the Green River, Kentucky case study in Richter et al. 2003a). Specifically, national legislation or executive orders are warranted, calling for reviews of all federal dams and assessments of opportunities to better manage these facilities to support riverine biodiversity and ecosystem services. Allocation of a small portion of the revenues generated at federal hydroelectric power dams would greatly benefit ecosystem research and monitoring. Hydropower revenues, generated at the main dams of the Colorado River Storage Project (Richter et al. 2003a), support both the Grand Canyon Monitoring and Research Center and the monitoring element of the Recovery Implementation Program for Endangered Fish Species in the Upper Colorado River Basin. In South Africa, the federal Water Research Commission receives all its revenue from a tariff on national water consumption. These funds are then distributed to the research community.

As examples of successful engagement of scientists in water management accumulate (such as the studies below Glen Canyon and Flaming Gorge dams mentioned above),

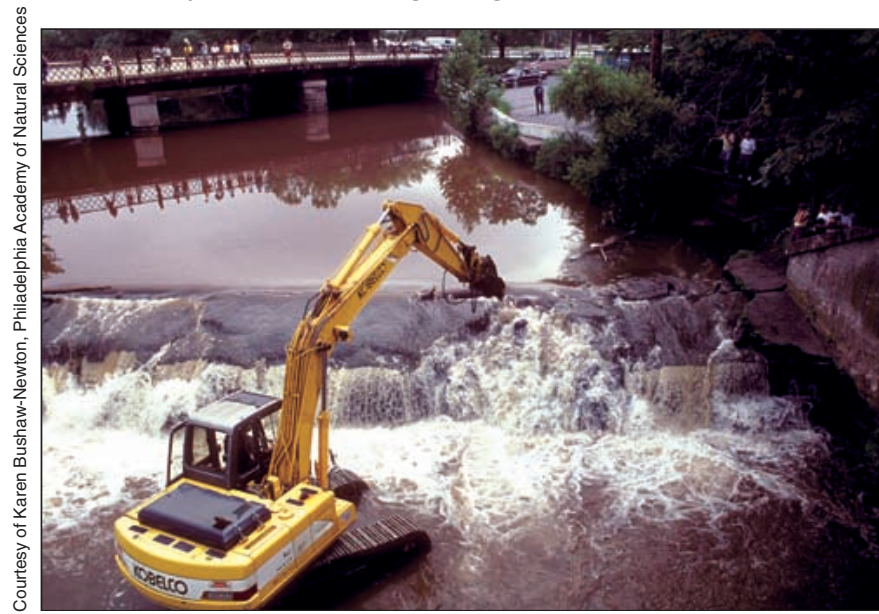

various organizations with non-research missions may well commit more funding to this kind of research. For example, scientists from the Nature Conservancy are working with the US Army Corps of Engineers in a set of adaptive management experiments to modify dam operations to enhance ecological conditions on a number of rivers, including the Green River in Kentucky (Richter et al. 2003a). The Tennessee Valley Authority's modified operation of their dams to improve downstream water quality (Bednarek 2002) provides another example of a new partnership between management and research. Broader initiatives are growing as well, such as those that link local community activities with state and federal funding initiatives. The Natural Heritage Trust's Rivercare Program, the Murray-Darling River Basin's Natural Resource Management Strategy in Australia, and the California Bay-Delta Program in the US are just a few examples. Although this is encouraging, much more is needed.

\section{Conclusions}

Achieving a more effective and sustainable balance between human and ecological needs for fresh water is one of the great challenges of this century. Population increases, economic development, and a changing climate will exacerbate water conflicts, leading to even more demands for sound science to inform decision making and achieve social and environmental goals. Society is now expending substantial resources to incorporate ecological goals into water management, and we have a right to expect appropriate returns on those investments. Our broad ecological understanding of river ecosystems the flow regime concept in particular - furnishes the framework within which society can balance economic and environmental objectives. At the same time, recent water conflicts make it apparent that we must continue to improve our science in support of decision making, while recognizing that outcomes can never be entirely certain.

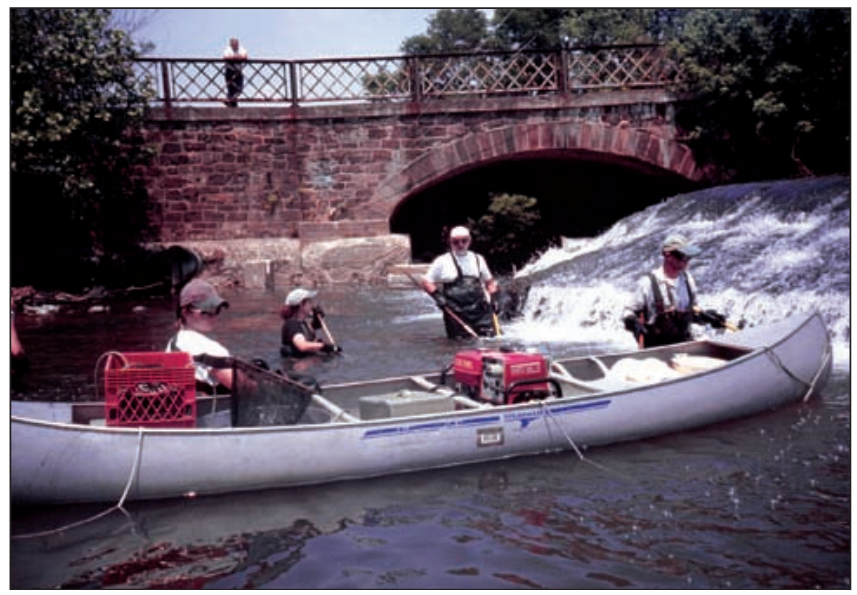

Figure 5. The effectiveness of dam removal as a method of river restoration is being evaluated in several regions of the US. (left) Scientists from Philadelphia's Patrick Center for Environmental Research study the removal of the 2-m high milldam on Manatawny Creek in southeast Pennsylvania in Aug 2002, (right) after documenting ecological conditions before the dam was removed (BushawNewton et al. 2002). 
Our conceptual understanding of river ecosystem function now needs to be bolstered with more detailed and specific knowledge, which is best gained by learning experimentally from present and future management practices coupled with a synthesis of existing knowledge from ongoing case studies. For a relatively small investment of funds, and with a perhaps more challenging realignment of research priorities through professional incentives, we can take advantage of numerous opportunities for learning that are otherwise being missed. Key elements in our alternative model for advancing river science include an expanded spatial scale that extends to entire, large ecosystems, the engagement of stakeholders and the public in defining shared visions and objectives, a greater emphasis on learning through case studies, which can teach us what is context-specific and what is general, and finding innovative ways to match a relatively small investment in research and evaluation to complement much larger investments in infrastructure and help repair damaged ecosystems through successful partnerships. We believe these four steps will result in scientific and social gains that will demonstrably improve river management and sustainability, thereby providing long-term social benefits that will more than repay the initial investments.

\section{Acknowledgments}

This article evolved from a science workshop held in Fort Collins, Colorado, in July 2001. We thank the other participants (Mark Bain, Carol Couch, Cliff Dahm, David Galat, Jackie King, Heather MacKay, Frank Magilligan, Ruth Mathews, David Merritt, Todd Wellnitz), and the NSF for partial sponsoring support (NSF grant DEB 0108832). Nicole Rousmanier, Katherine Ransel, Allison Kozak, and Roger Thomas provided valuable assistance with figures. We also thank Steve Carpenter and Sandra Postel for comments on an early draft.

\section{References}

Allen TFH, Tainter JA, Pires JC, and Hoekstra TW. 2001. Dragnet ecology - "Just the facts, ma'am": the privilege of science in a postmodern world. BioScience 51: 475-85.

Arthington $\mathrm{AH}$ and Pusey BJ. Flow restoration and protection in Australian rivers. River Res Appl 19. In press.

Baron JS, Poff NL, Angermeier PL, et al. 2002. Meeting ecological and societal needs for freshwater. Ecol Appl 12: 1247-60.

Bednarek AT. 2002. Dams and decision-making: balancing socioeconomic and ecological considerations ( $\mathrm{PhD}$ dissertation). Philadelphia, PA: University of Pennsylvania.

Benda LE, Poff NL, Tague C, et al. 2002. How to avoid train wrecks when using science in environmental problem solving. BioScience 52: 1127-36.

Bradshaw GA and Borchers JG. 2000. Uncertainty as information: narrowing the science-policy gap. Conserv Ecol 4: 7. www.consecol.org/vol4/iss1/art7.

Bunn SE and Arthington AH. 2002. Basic principles and ecological consequences of altered flow regimes for aquatic biodiversity. Environ Manage 30: 492-507.

Bushaw-Newton KL, Hart DD, Pizzuto JE, et al. 2002. An integrative approach towards understanding ecological responses to dam removal: the Manatawny Creek study. J Am Water Res Assoc 38: 1-19.

CALFED (California Bay-Delta Authority) 2001. http://calfed .ca.gov. Viewed 25 February 2003.

Carpenter SR. 2002. Ecological futures: building an ecology of the long now. Ecology 83: 2069-83.

Cullen P, Marchant R, and Mein R. 2003. Review of science underlying the assessment of the ecological condition of the Lower Balonne System. Independent scientific review panel report to the Queensland Government. Queensland Natural Resources and Mines Report Number 03025, The State of Queensland. $54 \mathrm{pp}$.

Folke C, Carpenter S, Elmqvist T, et al. 2002. Resilience and sustainable development: building adaptive capacity in a world of transformations. Ambio 31: 437-40.

GCMRC (Grand Canyon Monitoring and Research Center) 2003. www.gcmrc.gov. Viewed 9 May 2003.

Hart DD, Johnson TE, Bushaw-Newton KL, et al. 2002. Dam removal: challenges and opportunities for ecological research and river restoration. BioScience 52: 669-82.

Hobbs BF, Ludsin SA, Knight RL, et al. 2002. Fuzzy cognitive mapping as a tool to define management objectives for complex ecosystems. Ecol Appl 12: 1548-65.

Holling CS and Allen CR. 2002. Adaptive inference for distinguishing credible from incredible patterns in nature. Ecosystems 5: 319-28.

Holling CS, Gunderson LH, and Walters CJ. 1994. The structure and dynamics of the Everglades system: guidelines for ecosystem restoration. In: Davis SM and Ogden JC (Eds). Everglades: the ecosystem and its restoration. Delray Beach, FL: St. Lucie Press. p 741-56.

ISG (Independent Science Group) 2000. Return to the river: restoration of salmonid fishes in the Columbia River ecosystem. Report 2000-12. Portland, OR: Northwest Power Planning Council. www.nwppc.org. Viewed 21 November 2002.

King JM, Brown C, and Sabet H. A scenario-based holistic approach to environmental flow assessments for rivers. River Res Appl 19. In press.

Kingsford RT. 2000. Ecological impacts of dams, water diversions and river management on floodplain wetlands in Australia. Austral Ecol 25: 109-27.

Levy S. 2003. Turbulence in the Klamath River Basin. BioScience 53: 315-20.

Ludwig D. 2001. The era of management is over. Ecosystems 4: 758-64.

MDBI (Murray-Darling Basin Initiative) 2003. www.mdbc .gov.au/index.htm. Viewed 9 May 2003.

Muth RT, Crist LW, LaGory KE, et al. 2000. Flow and temperature recommendations for endangered fishes in the Green River downstream of Flaming Gorge Dam. Final Report, Project FG53. Lakewood, CO: Upper Colorado Endangered Fish Recovery Program.

Naiman RJ, Bunn SE, Nilsson C, et al. 2002. Legitimizing fluvial ecosystems as users of water. Environ Manage 30: 455-67.

Naiman RJ, Magnuson JJ, McKnight DM, et al. 1995. The freshwater imperative: a research agenda. Washington, DC: Island Press.

NPS (National Park Service) 1996. River renewal: restoring rivers through hydropower dam relicensing. Washington, DC: National Park Service.

NRC (National Research Council) 2002a. Grand challenges in environmental sciences. Washington, DC: National Academy.

NRC. 2002b. The Missouri River ecosystem: exploring the prospects for recovery. Washington, DC: National Academy.

NRC. 2002c. Scientific evaluation of biological opinions on endangered and threatened fishes in the Klamath River Basin: interim report. Washington, DC: National Academy.

Nilsson C, Pizzuto JE, Moglen GE, et al. Ecological forecasting and 
running water systems: Challenges for economists, hydrologists, geomorphologists, and ecologists. Ecosystems. In press.

Patten DT and Stevens LE. 2001. Restoration of the Colorado River ecosystem using planned flooding. Ecol Appl 11: 633-34.

Pfirman S and the AC-ERE. 2003. Complex environmental systems: synthesis for earth, life and society in the 21st century. Washington, DC: National Science Foundation.

Pickett, STA, Jones CG, and Kolassa J. 1994. Ecological understanding: the nature of theory and the theory of nature. San Diego, CA: Academic Press.

Pigram JJ. 2000. Viewpoint - options for rehabilitation of Australia's Snowy River: an economic perspective. Regul Rivers 16: 363-33.

Poff NL, Allan JD, Bain MB, et al. 1997. The natural flow regime: a paradigm for river conservation and restoration. BioScience 47: 769-84.

Poff NL, Brinson M, and Day JB. 2002. Freshwater and coastal ecosystems and global climate change: a review of projected impacts for the United States. Arlington, VA: Pew Center on Global Climate Change. www.pewclimate.org/projects/index_ environment.cfm.

Postel SL, Daily GC, and Ehrlich PR. 1996. Human appropriation of available fresh water. Science 271: 785-88.

Pringle CM. 2001. Hydrologic connectivity and the management of biological reserves: a global perspective. Ecol Appl 11: 981-88.

Puckridge JT, Sheldon F, Walker KF, and Boulton AJ. 1998. Flow variability and the ecology of large rivers. Marine Freshw Res 49: $55-72$.

Reckhow KH. 1999. Water quality prediction and probability network models. Can J Fish Aquat Sci 56: 1150-58.

Richter BR, Baumgartner JV, Braun DP, and Powell J. 1998. A spatial assessment of hydrologic alteration within a river network. Regul Rivers 14: 329-40.

Richter BR, Mathews R, Harrison DL, and Wigington R. 2003a. Ecologically sustainable water management: managing river flows for ecological integrity. Ecol Appl. 13: 206-24.

Richter BD, Meyer JL, Lutz K, and Warner A. 2003b. Specifying water flow requirements to support river health. Proceedings of the 2003 Georgia Water Resources Conference; 23-24 April 2003; University of Georgia, Athens, GA. Athens, GA: University of Georgia Institute of Ecology. p 457-59.
Robson D. 2002. Blow for irrigation schemes. The Press (New Zealand) 31 Oct 2002. www.stuff.co.nz/inl/print/0,1478, 2099898a6528,00.html. Viewed 21 November 2002.

Rogers KH. Adopting a heterogeneity paradigm: implications for biodiversity management in protected areas. In: du Toit J, Rogers K, and Biggs H (Eds). The Kruger experience: ecology and management of savanna heterogeneity. Washington, DC: Island Press. In press.

Rogers KH, Roux D, and Biggs H. 2000. Challenges for catchment management agencies: lessons from bureaucracies, business and resource management. Water SA 26: 505-11.

Rogers KH and Bestbier R. 1997. Development of a protocol for the definition of the desired state of riverine systems in South Africa. Pretoria, South Africa: Department of Environmental Affairs and Tourism.

Rubin DM, Topping DJ, Schmidt JC, et al. 2002. Recent sediment studies refute Glen Canyon Dam hypothesis. Eos 83: 273-78.

Shabecoff P. 2000. Earth rising: American environmentalism in the 21st century. Washington DC: Island Press.

Stanley EH and Doyle MW. 2003. Trading off: the ecological effects of dam removal. Front Ecol Environ 1: 15-22.

Stanford JA, Snyder EB, Lorang MS, et al. 2002. The reaches project: ecological and geomorphic studies supporting normative flows in the Yakima River Basin, Washington. Final Report. Yakima, WA: US Bureau of Reclamation. www.wsdot. wa.gov/environment/streamlineact/subcommittee_docs/BOR_ Yakima_Report.pdf. Viewed 21 November 2002.

Stanford JA, Ward JV, Liss WJ, et al. 1996. A general protocol for restoration of regulated rivers. Regul Rivers 12: 391-414.

Vörösmarty CJ, Green P, Salisbury J, and Lammers RB. 2000. Global water resources: vulnerability from climate change and population growth. Science 289: 284-88.

Walters C. 1997. Challenges in adaptive management of riparian and coastal systems. Conserv Ecol 1: 1. www.consecol.org/vol1/ iss2/art1. Viewed 12 February 2003.

Walters C and Korman J. 1999. Cross-scale modeling of riparian ecosystem responses to hydrologic management. Ecosystems 2: 411-21.

WCD (World Commission on Dams) 2000. Dams and development: a new framework for decision making. London: Earthscan Publications. 